\title{
Sistem Pendukung Keputusan Kemajuan Yayasan Menggunakan Metode SMART ( Simple Multi Attribute Rating Technique) (Studi Kasus : Yayasan Pendidikan Daarut Taqwa Asyamsuriyyah Sabandar)
}

\author{
Fuad Nasher ${ }^{1}$; Muhammad Wisnu Fratama ${ }^{2}$ \\ Teknik Informatika, Universitas Suryakancana \\ fuad.nasher@gmail.com ; fwisnu97@gmail.com
}

\begin{abstract}
Abstrak
Yayasan Daarut Taqwa Asyamsuriyyah merupakan sebuah yayasan pendidikan yang berdiri sejak 2011 yang mengelola pendidikan formal dari tingkat usia dini diantaranya Pondok Pesantren, TPA/TKA/RA, PAUD, DTA, SMP IT, SMA IT dan pendidikan non formal. Yayasan ini perlu adanya peningkatan kualitas terutama dari bidang teknologi supaya dapat bersaing dengan yayasan pendidikan yang lainnya, pihak yayasan kesulitan untuk melihat kemajuan sekolah karena belum adanya sistem. Sistem yang dibangun untuk melihat kemajuan yayasan menggunakan metode SPK yaitu metode SMART. Dalam pembuatan Sistem tersebut menggunakan metoda pengembangan sistem berdasarkan paradigma Waterfall yang terdiri dari communication, planning, modeling, construction dan deployment. Kemudian untuk metoda perancangan sistem menggunakan konsep perancangan berbasis objek dimana menggunakan alat-alat perancangan seperti Use case Diagram, Swimlane diagram, Class Diagram, State Diagram dan Sequence Diagram. Aplikasi yang digunakan dalam pembuatan Sistem tersebut adalah sublime sebagai aplikasi pemograman PHP dan XAMPP sebagai DBMS nya. Dari analisis dilakukan, maka dihasilkan sebuah Sistem pengambilan Keputusan yang merupakan salah satu alternatif untuk digunakan yayasan dalam mengetahui nilai kemajuan sekolah.
\end{abstract}

Kata kunci: SMART, Sistem Pengambilan Keputusan

\section{Pendahuluan}

Pendidikan mempunyai peranan yang sangat penting bagi kemajuan bangsa ini, salah satu hal yang tidak dapat dilepaskan dari pendidikan yaitu prestasi dan prilaku peserta didik. Sekolah sebagai institusi pendidikan, mengembangkan berbagai sistem pembinaan yang sifatnya memotivasi dan mengembangkan potensi para siswa. Salah satu kegiatan untuk proses pengembangan potensi setiap siswa adalah melalui pemilihan siswa berprestasi. Kemudian untuk melakukan tolak ukur kemajuan sekolah, maka diperluakan suatu system yang mampu melakukan proses pengelolaan data kemajuan sekolah per tahun ajaran, sehingga dapat diketahui sekolah tersebut mengalami kemajuan atau kemunduranya. Salah satu metode yang bisa di terapkan di sekolah untuk mengukur kemajuannya yaitu menggunakan SPK. Sistem Penunjang Keputusan atau Decision Support System secara khusus didefinisikan sebagai sebuah sistem yang mendukung kerja seorang manajer maupun sekelompok manajer dalam memecahkan masalah semi terstruktur dengan cara memberikan informasi ataupun usulan menuju pada keputusan tertentu. (Hermawan, 2005). Ada beberapa metode dalam proses SPK, salah satu metode SPK yaitu metode SMART. Simple Multi Atribut Rating Technique (SMART) merupakan metode pengambilan keputusan multi kriteria menurut Edward pada tahun 1977.
Yayasan Daarut Taqwa Asyamsuriyyah merupakan sebuah yayasan pendidikan yang berdiri sejak 2011 yang mengelola pendidikan formal dari tingkat usia dini diantaranya Pondok Pesantren, TPA/TKA/RA, PAUD, DTA, SMP IT, SMA IT dan pendidikan non formal lain seperti Majlis Ta'lim, Kelompok Belajar/Pengajian malam serta satuan pendidikan yang sejenis. Namun untuk pendidikan formal khususnya SMP IT dan SMA IT baru didirikan 2 tahun kebelakang, Yayasan ini perlu adanya peningkatan kualitas terutama dari bidang teknologi supaya dapat bersaing dengan yayasan pendidikan yang lainnya, pihak yayasan kesulitan untuk mengukur kinerja pegawai dan untuk melihat kemajuan yayasan, pada saat ini pengukuran keberhasilan kemajuan kualitas dilakukan dengan melihat dari absen, sertifikat, prestasi, dan beasiswa yang didapat dan dilakukan dengan menghitung secara manual karena belum adanya sistem untuk melakukan hal tersebut.

Dalam pengimplementasian system monitoring kemajuan sekolah menggunaka data-data yang rinci sehingga hasil yang dikeluarkan dapat lebih maksimal. Sehingga dengan metode ini akan lebih memudahkan pihak yayasan dan lebih akurat. Serta untuk proses perhitunganya menggunakan metode SMART, dengan hasil akhir berupa ranking.

\section{Studi Literatur}

a. Sistem Pendukung Keputusan

Sistem Pendukung Keputusan adalah pendekatan berbasis komputer atau metodologi untuk mendukung 
pengambilan keputusan. Bagian paling penting dari SPK khas adalah data warehouse, yang merupakan subjek berorientasi, terpadu, waktu-varian, non-normalisasi, koleksi non-volatile data yang memungkinkan menganalisis sejumlah besar data dari berbagai sumber dengan hasil yang cepat (Turban, 2005).

\section{b. Metode SMART}

SMART ( Simple Multi Attribute Rating Technique ) merupakan metode pengambilan keputusan yang multiatribut yang dikembangkan oleh Edward pada tahun 1977. Teknik pembuatan keputusan multiatribut ini digunakan untuk mendukung pembuat keputusan dalam memilih antara beberapa alternatif. Setiap pembuat keputusan harus memilih sebuah alternatif yang sesuai dengan tujuan yang telah dirumuskan.Setiap alternatif terdiri dari sekumpulan atribut dan setiap atribut mempunyai nilai-nilai. Nilai ini dirata-rata dengan skala tertentu. Setiap atribut mempunyai bobot yang menggambarkan seberapa penting dibandingkan dengan atribut lain. Pembobotan dan pemberian peringkat ini digunakan untuk menilai setiap alternatif agar diperoleh alternatif terbaik. Pembobotan pada SMART ( Simple Multi Attribute Rating Technique ) menggunakan skala antara 0 sampai 1, sehingga mempermudah perhitungan dan perbandingan nilai pada masing-masing alternatif..

\section{c. Pengertian Web}

Website merupakan fasilitas internet yang menghubungkan dokumen dalam lingkup lokal maupun jarak jauh. Dokumen pada website disebut dengan web page dan link dalam website memungkinkan pengguna bisa berpindah dari satu page ke page lain (hyper text), baik diantara page yang disimpan dalam server yang sama maupun server diseluruh dunia. Pages diakses dan dibaca melalui browser seperti Netscape Navigator, Internet Explorer, Mozila Firefox, Google Chrome dan aplikasi browser lainnya (Hakim Lukmanul, 2004)

\section{Analisa Masalah}

Yayasan Yayasan Daarut Taqwa Asyamsuriyyah merupakan sebuah yayasan pendidikan yang berdiri sejak 2011 yang mengelola pendidikan formal dari tingkat usia dini diantaranya Pondok Pesantren, TPA/TKA/RA, PAUD, DTA, SMP IT, SMA IT dan pendidikan non formal lain seperti Majlis Ta'lim, Kelompok Belajar/Pengajian malam serta satuan pendidikan yang sejenis. Namun untuk pendidikan formal khususnya SMP IT dan SMA IT baru didirikan 2 tahun kebelakang, Yayasan ini perlu adanya peningkatan kualitas terutama dari bidang teknologi supaya dapat bersaing dengan yayasan pendidikan yang lainnya, pihak yayasan kesulitan untuk mengukur kinerja pegawai dan untuk melihat kemajuan yayasan, pada saat ini pengukuran keberhasilan kemajuan kualitas dilakukan dengan melihat dari absen, sertifikat, prestasi, dan beasiswa yang didapat dan dilakukan dengan menghitung secara manual karena belum adanya sistem untuk melakukan hal tersebut. Dengan Sistem Pendukung Keputusan kemajuan yayasan dapat dilihat dengan mudah..
Tabel 1 Data Kriteria

\begin{tabular}{|c|l|c|c|}
\hline No & Kriteria / Perspektif & Bobot & Kode \\
\hline 1 & Kepuasan Siswa & 0.4 & $\mathrm{C} 1$ \\
\hline 2 & Keuangan & 0.3 & $\mathrm{C} 2$ \\
\hline 3 & Proses Bisnis Internal & 0.2 & $\mathrm{C} 3$ \\
\hline 4 & $\begin{array}{l}\text { Pertumbuhan dan } \\
\text { pembelajaran }\end{array}$ & 0.1 & $\mathrm{C} 4$ \\
\hline
\end{tabular}

Tabel 2 Data Subkriteria

\begin{tabular}{|c|c|c|c|}
\hline $\begin{array}{l}\mathrm{N} \\
\mathrm{o}\end{array}$ & Kriteria & Subkriteria & Nilai \\
\hline \multirow{4}{*}{1} & \multirow{4}{*}{ Kepuasan Siswa } & Sangat puas & 100 \\
\hline & & Puas & 70 \\
\hline & & Tidak Puas & 50 \\
\hline & & $\begin{array}{ll}\text { Sangat } & \text { Tidak } \\
\text { Menguasai } & \\
\end{array}$ & 0 \\
\hline \multirow{3}{*}{2} & \multirow{3}{*}{ Keuangan } & $\begin{array}{l}\text { Mendapat } \\
\text { keuntungan }\end{array}$ & 100 \\
\hline & & $\begin{array}{l}\text { Tidak mendapat } \\
\text { untung }\end{array}$ & 50 \\
\hline & & Mendapat kerugian & 0 \\
\hline \multirow{3}{*}{3} & \multirow{3}{*}{$\begin{array}{l}\text { Proses } \\
\text { Internal }\end{array}$} & Sesuai Planning & 100 \\
\hline & & $\begin{array}{ll}\text { Kurang } & \text { sesuai } \\
\text { planning } & \\
\end{array}$ & 50 \\
\hline & & $\begin{array}{ll}\text { Tidak } & \text { Sesuai } \\
\text { planning } & \end{array}$ & 0 \\
\hline \multirow{5}{*}{4} & \multirow{5}{*}{$\begin{array}{l}\text { Pertumbuhan dan } \\
\text { pembelajaran }\end{array}$} & Sangat memuaskan & 100 \\
\hline & & Memuaskan & 80 \\
\hline & & Cukup & 60 \\
\hline & & Tidak memuaskan & 40 \\
\hline & & $\begin{array}{ll}\begin{array}{l}\text { Sangat } \\
\text { memuaskan }\end{array} & \text { tidak } \\
\end{array}$ & 0 \\
\hline
\end{tabular}

Tabel 3 1.Analisis Perhitungan

\begin{tabular}{|c|c|c|c|}
\hline No & Jenjang & Nama Kriteria & $\begin{array}{l}\text { Nilai } \\
\text { Utility }\end{array}$ \\
\hline \multirow{4}{*}{1} & \multirow{4}{*}{ TK } & Kepuasan Siswa & 100 \\
\hline & & Keuangan & 50 \\
\hline & & Proses Bisnis Internal & 100 \\
\hline & & $\begin{array}{l}\text { Pertumbuhan Dan } \\
\text { Pembelajaran }\end{array}$ & 60 \\
\hline \multirow{4}{*}{2} & \multirow{4}{*}{ SMP IT } & Kepuasan Siswa & 70 \\
\hline & & Keuangan & 100 \\
\hline & & Proses Bisnis Internal & 100 \\
\hline & & $\begin{array}{ll}\text { Pertumbuhan } & \text { Dan } \\
\text { Pembelajaran } & \\
\end{array}$ & 80 \\
\hline \multirow{4}{*}{3} & \multirow{4}{*}{ SMA IT } & Kepuasan Siswa & 100 \\
\hline & & Keuangan & 50 \\
\hline & & Proses Bisnis Internal & 50 \\
\hline & & $\begin{array}{l}\text { Pertumbuhan } \\
\text { Pembelajaran }\end{array}$ & 40 \\
\hline
\end{tabular}

Tabel 4 Nilai Maksimal

\begin{tabular}{|c|c|}
\hline Kriteria & Nilai Maksimum \\
\hline $\mathrm{C} 1$ & 100 \\
\hline $\mathrm{C} 2$ & 100 \\
\hline $\mathrm{C} 3$ & 100 \\
\hline $\mathrm{C} 4$ & 100 \\
\hline
\end{tabular}


Rumus perhitungan:

$$
u_{i}\left(a_{i}\right)=100 \frac{\left(C_{\max }-C_{\text {outi }}\right)}{\left(C_{\max }-C_{\min }\right)} \%
$$

\section{Perhitungan Untuk TK}

a. Bobot Nilai Kepuasan Siswa

$100 \frac{100-0}{100-0}=1(100 \%)$

b. Bobot Nilai Keuangan

$100 \frac{50-0}{100-0}=0.50(50 \%)$

c. Bobot Nilai Proses Bisnis Internal

$100 \frac{100-0}{100-0}=1(100 \%)$

d. Bobot Nilai Pertumbuhan dan Pembelajaran

$$
100 \frac{80-0}{100-0}=0.80(80 \%)
$$

Perhitungan Untuk SMP IT

a. Bobot Nilai Kepuasan Siswa

$$
100 \frac{100-0}{100-0}=1(100 \%)
$$

b. Bobot Nilai Keuangan

$100 \frac{50-0}{100-0}=0.50(50 \%)$

c. Bobot Nilai Proses Bisnis Internal

$100 \frac{100-0}{100-0}=1(100 \%)$

d. Bobot Nilai Pertumbuhan dan Pembelajaran

$100 \frac{80-0}{100-0}=0.80(80 \%)$

Perhitungan Untuk SMA IT

e. Bobot Nilai Kepuasan Siswa

$100 \frac{100-0}{100-0}=1(100 \%)$

f. Bobot Nilai Keuangan

$100 \frac{50-0}{100-0}=0.50(50 \%)$

g. Bobot Nilai Proses Bisnis Internal

$100 \frac{100-0}{100-0}=1(100 \%)$

\begin{tabular}{|c|c|c|c|}
\hline \multicolumn{4}{|c|}{ Didapat nilai utility } \\
\hline $\mathrm{O}$ & Jenjang & Nama Kriteria & $\begin{array}{c}\text { Nilai } \\
\text { Normalisasi } \\
\text { Utility }\end{array}$ \\
\hline \multirow{4}{*}{1} & \multirow{4}{*}{$T K$} & Kepuasan Siswa & 1 \\
\hline & & Keuangan & 0.50 \\
\hline & & Proses Bisnis Internal & 1 \\
\hline & & $\begin{array}{l}\text { Pertumbuhan dan } \\
\text { Pembelajaran }\end{array}$ & 0.80 \\
\hline \multirow{4}{*}{2} & \multirow{4}{*}{$S M P$} & Kepuasan Siswa & 0.70 \\
\hline & & Keuangan & 1 \\
\hline & & Proses Bisnis Internal & 1 \\
\hline & & $\begin{array}{l}\text { Pertumbuhan dan } \\
\text { Pembelajaran }\end{array}$ & 0.80 \\
\hline \multirow{4}{*}{3} & \multirow{4}{*}{$S M A$} & Kepuasan Siswa & 1 \\
\hline & & Keuangan & 0.50 \\
\hline & & Proses Bisnis Internal & 0.50 \\
\hline & & $\begin{array}{l}\text { Pertumbuhan dan } \\
\text { Pembelajaran }\end{array}$ & 0.40 \\
\hline
\end{tabular}

h. Bobot Nilai Pertumbuhan dan Pembelajaran

$100 \frac{80-0}{100-0}=0.80(80 \%)$
Perhitungan akhir untuk TK

$=(0.4 * 1)+(0.3 * 0.50)+(0.2 * 1)+(0.1 * 0.80)$

$=0.4+0.15+0.2+0.08$

$=0.83$

Perhitungan akhir untuk SMP IT

$=(0.4 * 0.70)+(0.3 * 1)+(0.2 * 1)+(0.1 * 0.80)$

$=0.28+0.3+0.2+0.08$

$=0.86$

Perhitungan akhir untuk SMA IT

$=(0.4 * 1)+(0.3 * 0.50)+(0.2 * 0.50)+(0.1 * 0.40)$

$=0.4+0.15+0.1+0.04$

$=0.69$

Ranking akhir

\begin{tabular}{|l|l|l|l|}
\hline NO & Jenjang & Nilai Akhir & Rangking \\
\hline 1 & TK & 0.83 & 2 \\
\hline 2 & SMP IT & 0.86 & 1 \\
\hline 3 & SMA IT & 0.69 & 3 \\
\hline
\end{tabular}




\section{Analisis Kebutuhan Perangkat Lunak}

Agar sistem tersebut dapat berjalan maksimal maka dibutuhkan perangkat lunak yang dibutuhkan sebagai berikut:
1) Xampp
2) Sublime Text 3
3) Browser Google Chrome

\section{Kebutuhan Perangkat Keras}

Spesifikasi perangkat keras yang digunakan adalah sebagai berikut:

1. Processor Intel Core I3.

2. Sistem operasi windows 7.

3. Memori membutuhkan RAM 2 GB.

4. Untuk hard disk minimal size yang kosong sebesar 500 Gigabyte

5. Mouse, keyboard, dan monitor sebagai peralatan antarmuka

\section{Pengujian}

Tabel 5 Pengujian

\begin{tabular}{|l|l|l|c|}
\hline $\begin{array}{c}\text { Pengujia } \\
\mathrm{n}\end{array}$ & Keterangan & $\begin{array}{l}\text { Hasil } \\
\text { Pengamatan }\end{array}$ & $\begin{array}{c}\text { Kesesuai } \\
\text { an }\end{array}$ \\
\hline \multirow{4}{*}{$\begin{array}{l}\text { Proses } \\
\text { penilaia } \\
\text { n }\end{array}$} & $\begin{array}{l}\text { Melakukan } \\
\text { normalisai } \\
\text { nilai } \\
\text { persubkriter } \\
\text { ia }\end{array}$ & $\begin{array}{l}\text { Menghitung } \\
\text { nilai } \\
\text { normalisasi } \\
\text { persubkriter } \\
\text { ia }\end{array}$ & Sesuai \\
& $\begin{array}{l}\text { Melakukan } \\
\text { perhitungan } \\
\text { total } \\
\text { persubkritei } \\
\text { a }\end{array}$ & $\begin{array}{l}\text { Melakukan } \\
\text { proses } \\
\text { perhitungan } \\
\text { nilai } \\
\text { keseluruhan } \\
\text { persubkriter }\end{array}$ & sesuai \\
& & Melakukan & Sesuai \\
\hline
\end{tabular}

\begin{tabular}{|c|l|l|c|}
\hline $\begin{array}{c}\text { Pengujia } \\
\mathrm{n}\end{array}$ & Keterangan & $\begin{array}{c}\text { Hasil } \\
\text { Pengamatan }\end{array}$ & $\begin{array}{c}\text { Kesesuai } \\
\text { an }\end{array}$ \\
\hline & $\begin{array}{l}\text { perhitungan } \\
\text { keseluruhan }\end{array}$ & $\begin{array}{l}\text { perhitungan } \\
\text { nilai } \\
\text { keseluruhan }\end{array}$ & \\
\hline
\end{tabular}

7. Simpulan

Setelah melakukan pengujian di dapat bahwa aplikasi ini dapat membantu pihak yayasan dalam melihat kemajuan yayasan. Untuk meningkatkan kinerja pada Sistem Penunjang Keputusan yang penulis buat ada beberapa saran-saran yang dapat penulis sarankan antara lain :

a. Sistem tersebut alangkah lebih baik lagi jika dimasukan sistem keamanan agar data yang ada dapat terjamin kerahasiaannya.

b. Untuk pengembangan selanjutnya sistem dapat terintegrasi dengan sistem lain agar dapat otomatis dalam penginputan datanya.

\section{Daftar Pustaka}

[1.] Amsyah, Z. (2005). Manajemen Sistem Informasi. Jakarta : Gramedia Pustaka Utama.

[2.] Kusrino. (2007). Strategi Perancangan dan Pengelolaan Basis Data. Yogyakarta: ANDI.

[3.] Parsimin. (2013). Membangun Sistem Informasi Berbasis Website Pada Smp Negeri 4 Purwanegara. Yogyakarta: Amikom.

[4.] Sinamarta, J. (2010). Rekayasa Perangkat Lunak. Yogyakarta: Andi.

[5.] Nofriansyah, Dicky, \& Defit, Sarjon (2017) Multi Criteria Decision Making (MCDM) pada Sistem Pendukung Keputusan. Yogyakarta:Deepublish

[6.] Yulianto, \& Ardhian, A. (2006). Sistem Informasi Penjualan. Yogyakarta: Andi. 